\title{
Passivity in Aesthetic Experience: Husserlian and Enactive Perspectives
}

\author{
Simon Høffding and Tone Roald
}

\begin{abstract}
This paper argues that the Husserlian notion of "passive synthesis" can make a substantial contribution to the understanding of aesthetic experience. The argument is based on two empirical cases of qualitative interview material obtained from museum visitors and a world-renowned string quartet, which show that aesthetic experience contains an irreducible dimension of passive undergoing and surprise. Analyzing this material through the lens of passive syntheses, helps explain these experiences as well as the sense of subject-object fusion that occurs in some of the most intense forms of aesthetic experience. These analyses are then contrasted with a potentially contradicting take on aesthetic experience from a recent trend in cognitive science, namely enactive aesthetics, which insists on the active subjective construction and sensemaking of aesthetic experience. Finally we show that the two positions are in fact compatible.
\end{abstract}

Keywords: Husserlian phenomenology, passive synthesis, enactive aesthetics, artworks in museums, musical absorption. 


\section{Introduction ${ }^{\mathrm{i}}$}

In this paper, we demonstrate how an important element in Husserl's thinking on subjectivity, namely his work on "passive synthesis" or just "passivity" is central for a phenomenological theory of aesthetic experience. Passive syntheses designate a substratum of subjectivity upon which "egoic" acts such as willing, choosing and deciding rest. We argue that such syntheses are at the heart of intense aesthetic experience and help to explain the experience of being moved or carried away, as well as the putative experiences of subject-object fusion. Husserl is not known as an important thinker of aesthetics, his main contribution in this field being on "image consciousness" in Ideen I. "Our argument, however, suggest a novel rapprochement between Husserlian scholarship and aesthetics.

The argument rests on two empirical cases: qualitative interviews with museum visitors and expert musicians. From museum visitors, we are focusing on descriptions of intense and memorable experiences with art within a greater framework of understanding the role of pre-reflective self-awareness in aesthetic experience. For the musicians, also within a greater framework of describing the overall phenomenology of musical absorption, we in this paper, focus on performing and undergoing experiences of feeling that the music is unfolding on its own as well as the rare and intense experiences of radical transformations of selfawareness sensed as either a kind of black-out or hyper-presence. We then present the Husserlian explication of passive synthesis to demonstrate how it develops our understanding of the two cases. In particular, these analyses highlights the sense in which we are not only initiators, but also undergoers of experience and help explain how it is possible to feel that one is merging with an aesthetic object or even one's surroundings, i.e. how a self-other blurring can manifest. These analyses are not merely meant to highlight Husserl's potential for phenomenological aesthetics, but can also encompass theoretical advances in cognitive science, more particularly, enactive aesthetics, which stresses the active and explorative nature of perception in aesthetic experience. iii The enactive proposal stressing activity is prima facie at odds with the Husserlian emphasis on passivity. We show, however, that on the one hand, Husserl's is a specific and technical term and, on the other hand, that the enactive usage is a response to computationalism in cognitive science and philosophy of mind. In other words, the notions of activity and passivity within the two traditions are not equivocal and hence it is not contradictory to claim that aesthetic experience can be both inherently passive (in the phenomenological sense) and inherently active (in the enactive sense). 


\section{The phenomenology of aesthetic and artistic experience}

Before beginning, let us delineate the scope of our argument. We are not in the business of providing necessary and sufficient conditions of aesthetic experience. In fact, we have no prior or special commitment to aesthetic experience as a bounded phenomenon. For the purposes of the present paper, employing this term is a pragmatic choice: people say that they have stimulating, memorable and meaningful experiences with seeing paintings, listening to or performing music. Whatever it is that makes it so, in the context of art exposure, we call aesthetic experience. ${ }^{\text {iv }}$

The material about experience with visual art is generated in accordance with the methodology of phenomenological psychology as set forth by Giorgi ${ }^{\vee}$ while those of the experience of music performance are generated with methods from ethnography as prescribed primarily by Ravn, ${ }^{\text {vi }}$ but also inspired by Gallagher's "front loaded phenomenology"vii and Petitmengin's "microphenomenology" viii One is justified in doubting the epistemic integrity of the interdisciplinary endeavor of phenomenologically informed qualitative interviews. Such doubt potantially targets a number of complex problems pertaining primarily to epistemology and methodology each of which deserves detailed and direct responses. We have provided such elsewhere, defending the claim that interview-based analyses, when employed in a methodologically rigorous way, can yield important insights, clarifications, and challenges useful for phenomenology. ${ }^{i x}$ For the sake of the current argument, we will not rehearse this lengthy defense here.

The first set of interviews were collected in regard to an ongoing research project on aesthetic experience with visual arts at Esbjerg Museum of Art as well as the National Art Gallery in Denmark. The following statements are examples of how museum visitors describe their intense experiences with art. ${ }^{x}$ The anonymized examples are selected from about 45 hours of interviewing and exemplify what is common to many of the descriptions. When interviewing museum visitors about their experiences with works of art, they mention being affected in involuntary and bodily ways in the sense of having immediate bodily reactions to the works of art, be it "a bubble of happiness" in the chest, or a feeling of "repulsion" and "nausea". They talk about memories that appear spontaneously, they talk about surprise, about experiencing something unknown, and about being led to follow what they perceive to be the artist's intentions. They also mention feelings of being overwhelmed, affected, and pulled into the picture. A visitor, Stefan, for instance, says that seeing the paintings by Andre Derain, is "shocking", and affects him "violently." He becomes "touched", "dizzy", and "short of breath". The pictures overwhelm him, inducing astonishment and a sense of feeling vanquished. This vocabulary, repeated several times throughout the 
interview, indicates that the artworks affect him in a way in which he has no say. He simply experiences what the work of art does to him. He had similar experiences with Amedeo Modigliani's paintings: the experience was very "strong" and "violent". This feeling of "violence" is physical - it affects his breathing and he can become dizzy. It is a "grand" encounter that "touches" him, as if the painting "hits him". The feeling of intensity transitions into a feeling of tiredness when he leaves the exhibit. Somewhat differently, Siv explains how it is "overstimulating" to visit art museums. It is a "bombardment" of her senses, so intense that she usually prefers nature over art. Nevertheless, there are experiences with art that she really values. For instance, once visiting a sculpture garden with the works of Barbara Hepworth: she is in a pleasant mood and it is lovely day, and suddenly she comes across an abstract sculpture which affects her like "a bolt from the blue." She feels overwhelmed, "touched", and starts to cry. Embarrassed about crying in public she leaves the sculpture, but returns to it after a while. She cries again, but now it is not so surprising to her. It is still mysterious to her why she cries as it is not an easily defined emotion like happiness or sadness, but is an experience she remembers with gratitude. ${ }^{x i}$ Stefan's and Siv's experiences share the feature of being strongly affected, they share an opening or receptivity that we shall find once again in the descriptions musicians give of their performances.

As we move on the next set of interviews with the musicians, it might be objected that the experience of visiting a museum cannot be contained within the same category as that of performing as a professional musician. We are not arguing that these two activities are identical, even if we see no principled reason why one could not have an aesthetic experience of one's own performance - an argument, which Barbara Montero advances in the context of being a dancer. ${ }^{\text {xii }}$ Clearly it makes a difference whether one is merely enjoying someone else's artistic creation or whether one is enjoying the creation, which happens to be the creation one is currently bringing about. However, it is interesting to note that remarkable experiences of these two activities share some structural similarities, which will be brought out in the subsequent analysis. The presence of such similarities suggest that it might ultimately be possible to construct a coherent phenomenology of aesthetic experience, but that is an argument to be made elsewhere.

In this section, we rely on a set of phenomenological interviews with the Danish String Quartet (DSQ), a world-famous ensemble performing and recording the "classic" classical repertoire, such as Mozart and Beethoven, as well as Nordic folk music. xiii The following material is picked out from about 17 hours of interviewing, as relevant for the present argument and thus composes only a fragment of the material and ideas within it, conducted with the aim of understanding the overall phenomenology of musical absorption. ${ }^{\text {xiv }}$ One of the main theoretical insights availed by the investigation with the DSQ is that musical absorption - although encompassing a multitude of intentionalities and mental states - can be grasped as a 
coherent phenomenon when assessed from the central view point of a change in the sense of agency or the sense of passivity. ${ }^{\mathrm{xv}}$ The DSQ members have spent thousands of hours training their bodily and expressive skills. They do not need to focus intentionally on the movement of their fingers and arms (though they can and sometimes do) to make their bodies obey the commands of the music when performing. In other words, they have developed the ability to play in an automatic fashion or to let the body "play on its own". It is from this fact of the intentionality of bodily expertise that our understanding of passivity must depart.

The DSQ violinist Frederik Øland, when trying to describe the most usual way he experiences performing, says the following

But you can perhaps say that what we're striving for at a technical level, that is to be...that it is coming by itself and that you are not too aware of it, that you do not spend any energy on it, that you just have this that it is coming by itself, but that you are aware of it maintaining itself.

Here Frederik does not attribute primary agency to himself, but relegates it to this automatic body, such that "you do not have to spend any energy", or such that music "comes by itself" accompanied by an observational stance of awareness of "it maintaining itself". The other violinist, Rune Tonsgaard mentions that: "you're surprised about how much the fingers remember themselves. Let the fingers play. Just use the activity of the brain not on what you're playing. Let go and think about something else." The performance has to unfold on its own. The fingers, not even agentially mentioned as "my fingers" but as anonymous fingers, should be allowed to play on their own. This automaticity of the body and self-unfolding nature of the music played in this way allows the musician to direct his attention elsewhere, for instance mentally preparing for a difficult passage, engaging in mental imagery that changes the sounds or evoking certain emotions that enhance the cohesion of the ensembles' sound. The sense of automaticity entails neither that the musicians do not know what they are doing, nor that they are not aware of the way the music unfolds, nor that they feel possessed or out of control. Rather, many active choices regarding interpretation, imagery, expression and so on are made. ${ }^{\text {vi }}$ But such choices can only be made when based on this skilled and flexible automaticity, which gives rise to the sense that the music is unfolding on its own. The automaticity involved in the sense of music unfolding grounds an affective dimension of performance: the experience of being moved by, or drawn into a piece of music necessarily depends on such skilled and habitual processes beyond the command of one's will and intentions.

After this general outline of musical absorption, let us turn to more specific experiences of more intense forms of absorption, where it becomes even clearer that the music unfolds in a way that transcends the musician's immediate will or sense of choice, here from the DSQ cellist, Fredrik Sjölin 
I think I have an idea of where I'm going and then I think...for each tone you play, you could say it such that time was a long, long line and you had a lot of points on the line....so for each point you advance, then...it gives...it will give the premise for where the next point would be because the tone itself in a sense defines the next tone and so on because otherwise the phrase becomes unnatural. And therefore you're really in the tone you're really on and then it kind of gives itself how the next tone will become...You need a smooth [development] and therefore each tone, each and every vibrato, each and every oscillation, bowing, phrasing, everything builds towards how it is going to become and it is impossible to predict how it will play out. It depends on what you laid as ground.

Ok, but you...must, once you've practised it, know how it is going to play out?

No.

He adds that sometimes the DSQ surprise themselves for instance by playing in a different tempo than agreed on. They have been forced into this tempo and "cannot get out of it" at least if they want to stay faithful the musical impulse they are feeling. Experientially considered, the musician can be performing in this fashion because he is not the sole agent of the performance, which, in order not to "become unnatural", must develop according to its own logic ${ }^{\text {xvii }}$ and transcend and distribute the agency and activity of the individual musician. Theoretically considered, the musician retains full agency and control. He could, in principle, at any point choose to increase or decrease his tempo, play more loudly or stop altogether. But the DSQ members believe that doing so, imposing one's will onto the music in this way, is not actually playing the music in the way it is supposed to be played and that they can sense if one of the others is trying to force the music in a certain direction. From the perspective of their experience, they cannot stop in the middle of a concert. They cannot remain adequately receptive to what they are supposed to be doing, if they do not allow themselves to be guided by this will or logic of the music.

The experience of being led by the music can also induce a certain spatial reorientation by which the musician comes to see the performance at a distance, as if it is not himself playing. Here is Frederik $\varnothing$ land's description:

it is like...the feeling of looking over a large landscape and knowing that this landscape consists of insects and branches and roots and all kinds of things building up the whole thing, but you cannot see the individual parts, you just know that all of it is, contributes to the being and that you actually could affect the little things, but you don't want to because you want everything to be there and contribute.

Jazz musicians are also prone to this kind of experience. Jazz-violinist, Kristian Jørgensen, for instance, expresses that: 
you find yourself so much at ease in the situation, that you, it is someone else playing for you and you yourself are sitting out in the, you sit and enjoy the music back down behind the mixer [referring to the recording studio, where the producer mixes the recorded sound] with your feet up out in the control room and then it is just like, you've let go.

Surprisingly, Jørgensen is not here referring to mixing or producing someone else's recording. He is referring to himself performing a concert, but feeling as if he is sitting behind the mixer with an externalized, third person perspective on himself. It is rare for this kind of experience to come so much to the experiential foreground ${ }^{x v i i i}$ that it causes such an altered spatial self-perspective. Should there be evidence for a full-blown musical out-of-body experience, ${ }^{\text {xix }}$ we believe that the understanding of musical absorption as the coming to prominence of the sense of being led can account for its genesis: the music imposes a will on the musician, but the response is not merely my response. By "my response", we mean a response of predicting or choosing. Rather, the response to the will of the music, it is the response of a prepersonal, autonomous, and automatic body $y^{x x}$ that reacts to the musical commands rather than merely to my ideas and intentions. I register that a body transcending my control ${ }^{x \times i}$ performs the music and I develop an experiential perspective from which I simply can enjoy seeing this music-body interaction. I can sit "down behind the mixer" or fly out to look at the performance as a "large landscape" wishing not to interfere but let "everything be there and contribute".

Let us offer one final example of the phenomenology of intense musical absorption. On rare occasions musicians seem to lose themselves into this web of external force and enter into a conscious state, experienced in an overpowering absence of mental faculties also marked by a posterior absence of memory. DSQ cellist Fredrik Sjölin expresses it thus:

The deeper you are in, the less you observe the world around you...and I had this especially powerful experience.... where I completely disappeared. I remember that it was an incredibly pleasant feeling in the body. And it was incredibly strange to come back and at that point I spent a few seconds to realize where I had been. I had been completely gone and with no possibility of observing...It was this intense euphoric joy.

Fredrik is neither looking at himself from the outside, nor perceiving the commands of the music nor watching his fingers respond. He has left the scene entirely and moved to a rather impenetrable, perhaps sleeplike dimension of consciousness. All that is recalled, is the emotion of joy and a pleasant bodily sensation. Although rare, mind states identical or similar to this are consistently reported as a fond musical memory and even as a raison d'être for some musicians. ${ }^{\text {xxii }}$ 


\section{The phenomenology of passivity}

It now remains to be demonstrated how the Husserlian notion of "passive synthesis" is a particularly important dimension of the experiences presented. Our claim is that they can be understood as a coming to the fore of this passive dimension of consciousness that is normally in the background. This claim is parallel to that of Legrand, who argues that dancers develop a specialized "performative body"xxiii consisting in a coming the fore of a bodily, pre-reflective self-consciousness. We believe that the analysis of passivity in relation to aesthetic experience can make headway in understanding the sense of being overwhelmed and overpowered by an artwork or the sense in which the music can unfold "on its own" and the sense of subject-object blurring for instance experienced by Fredrik when he "completely disappears".

It is difficult to get a concrete and lucid grip on passive synthesis. Husserl's writing on the theme is scattered across several different volumes such as Analyses Concerning Active and Passive Synthesis, Ideas Pertaining to a Pure Phenomenology and to a Phenomenological Philosophy, and Experience and Judgment, which do not necessarily share a positive definition. A number of commentators have worked on the idea, ${ }^{\text {xxiv }}$ and we rely on them as their expositions are more focused, and quite frankly clearer, than Husserl's own. For our purposes, we suggest an all-encompassing negative definition, rendering passive synthesis as a dimension of consciousness that unfolds without egoic consciousness, that is, without processes of predicting, choosing, attending and willing. Steinbock calls it a "primordial regularity of sense-genesis in which the ego does not participate" that "characterizes a pre-reflective dimension of experience of pregivenness of object-like formations, a dimension that is founding for activity." ${ }^{\prime \times v}$ Another important characterization comes from Biceaga, who calls it a negotiator "between ownness and alterity". xxvi From Steinbock and Biceaga we understand that passive syntheses or passivity ${ }^{x \times v i i}$ is a dimension of consciousness that founds, or acts as, a meaning-making substratum for active mental cognitions and that regulates the distinction between self and other.

Referring to passive syntheses does not mean that the subject is passive or inert. Think of my simple perception of the tree outside my window. I direct my attention to it, but its appearance is not exhaustively explained by this attention. Husserls writes that: "We always pay attention to "features," no matter which, and while we are considering the thing from the viewpoint of one "feature, " at the same time it stands intentionally there as endowed with others." $x x v i i i$ ground constellation, the surroundings or other "features" - these familiar buildings, given from this particular angle in this particular light - enclosing it, partly constitute what makes it "this tree". And 
emotions of nostalgia and anticipation are likewise activated, as I see its first little spring leaves, reminding me of this season of lush growth and of the past springs during which I've seen the tree. None of these associations are actively or purposively initiated by me, but co-presented as immanent in the perception of the tree. Pre-reflective internal time consciousness is another passive synthesis. .xix Looking at the "same" tree for a while requires an awareness that the tree I saw five seconds ago is the same as the tree I am currently perceiving. But to establish this fact, I need not in a comparative, reflective act, mentally match the past tree with the present one. Rather, it is given as enduring in retention, a pre-reflective streaming of consciousness stretching from the present into the near past as well in protention stretching from the present into the near future. This streaming is a necessary condition of sensible object constitution and synthesized passively in the sense that there is nothing I can do to initiate or arrest it (perhaps with the exception of killing myself or taking some very potent drug). As a substratum, passivity is normally in the experiential background. It is not something we notice because it is what avails our perceptions and cognitions of the world. When I walk down the stairs, my intention to get to the street is in the foreground, while the many complex bodily processes that actually get me there remain unnoticed, in the background. ${ }^{x \times x}$

We normally take a stable and rather permanent distinction between self and other for granted. I am perfectly aware of the stairs and the street as objects and of myself as the subject moving. I never confound them (in non-pathological experience). In aesthetic experience, however, as seen in the cases of seeing works of art and of playing music, the boundary between self and other or subject and object seemingly becomes more porous or blurry. This is not a new claim but can be found in classical theories of aesthetics of, for instance, Benson, Dufrenne, Bullogh, Lipps, and Puffer. We also find significant references to this sense of blurring or merging in our interview material. For instance in the Danish National Art Gallery, Frederik states that in intense experiences with visual art "the pictures become landscapes one can enter into". He feels that he becomes a part of the world of the painting. An even stronger version of merging is found in his statement that, in intense experiences with art, "one is dissolved." In other words, his experience is not one where his ego plays a part, but where the work of art becomes who he is. Similarly, Lise describes that at the Van Gogh museum in Amsterdam, "everything else is left behind. You are simply just in that exhibit or the world, almost as it is." And Siv relates that "you disappear in it [the work of art]." She also describes how she feels that she is in the picture and takes on its perspective: She perceives the same horizon with sky and water as she imagines the birds in the picture to experience. ${ }^{x \times x i}$

Our empirical material, together with the abovementioned classical aestheticians, demonstrate subjectobject blurring or merging to be a phenomenon central to aesthetic experience. The Husserlian framework 
of passivity, however, offers to clarify our understanding of this unusual phenomenon by accounting for its conditions of possibility. One of the ways it does this, is through the idea of anonymity. An excellent commentator on Husserlian passivity, Anne Montavont writes:

The passive intention is certainly an intentional form, but it is an 'inauthentic' intentionality insofar as it does not yet mobilize an I...The passive intention, insofar as it does not arise from the I, insofar as it is not accomplished by the I, insofar as it is an event 'without' I, presents itself as an objective event that unfolds by itself. ${ }^{x \times x i}$

As Zahavi writes, passive syntheses are not accomplished by an I, but nevertheless occur to oneself, $x$ xxiii which is similar to Husserl's claim that passive synthesis is: "a proper field of nexuses, ones which run out by themselves as objective events, though they are subjectively produced." ${ }^{\prime \prime x i v}$ On an experiential level, the intentionality of passivity as "objective events that run out by themselves", but nevertheless occur to oneself or is "subjectively produced" is accompanied by a sense of anonymity, which in some cases can be experienced as an unusual distance to oneself or one's own body. Here we find the connection back to the empirical examples of musical absorption. Remember that Frederik Øland and Asbjørn Nørgaard from the DSQ experience seeing themselves from the outside, not wishing to "interfere". They experience that it is not primarily them playing, but that playing is something happening to them. The playing is not experienced as executed by "me", but it is also not pathologically disembodied as if someone else was doing the playing. Rather, it unfolds in an anonymous way.

When passivity is expressed in the experiential foreground, it manifests, for instance, in a sense of anonymity, the sense that something is happening in me or to me, that transcends my immediate will or sense of agency. ${ }^{x \times x}$ Anonymous experience involves what we might call a rarefied sense of self, exactly because it leads me to having experiences of which I do not perceive myself as initiator. Ordinary selfexperience consists in a double-edged me as initiator and as recipient, identical to what Gallagher calls the sense of agency and the sense of ownership. ${ }^{\text {xxvi }}$ In contrast, what happens when passivity comes to the fore is that the me as initiator is anonymized or emptied. ${ }^{\text {xxvii }}$ When otherwise external objects fill this empty slot, it gives rise to the experiential sense of fusion. We could imagine the DSQ musicians expressing the following scale of increasingly passive experience: "I am playing the music", "the body is playing the music" or "the music is playing me". The three utterances equally instantiate me as the owner or undergoer of the experience, but when it comes to me as initiator they work at three different levels of increasing rarefaction. In the first case, I, the willing and choosing ego, holds the place as initiator. In the second case, passivity starts to manifest more strongly and the initiator becomes a body which transcends my immediate will. In the third case, there is something not merely anonymous, but experienced more specifically as other, xxxviii namely the music (sometimes even experienced as the composer), which takes the 
place as initiator. It follows from this that the experiential dimension of an enlarged, distributed or extended sense of self is proportional to its degree of rarefaction. The more rarefied, the more worldly objects can be incorporated into the performing subject. It starts with the violin, but can end in dreamlike disoriented state in which everything blurs, like Fredrik Sjölin's experience of "disappearing". While this process of anonymization could be described as a gradual loss of agency, it could just as well be described as an expansion of agency going from a somewhat isolated "me" composed of my choices and predictions, to a systemic and open agency consisting of my particular habits, dispositions and skills in open exchange with the qualities of this instrument, this music, these co-performers, in this room at this time. ${ }^{\text {xxix }}$

In the aesthetic experience in art museums, we see a similar kind of passivity at play. When Siv is struck by a sculpture like a "bolt from the blue" she is overwhelmed and surprised because something unexpected, something of which she is not the initiator, happens to her. The sculpture activates feelings or memories in her that she did not evoke herself, and we thus find the sense of passivity through which she intensively senses owning an experience which does not coincide with an initiation on her part. In line with Husserl, we find that certain activations of the body and of one's emotions ${ }^{x l}$ can powerfully boost the experienced sense of passivity. After being led to tears, Siv moves away from the Hepworth sculpture and thus regulates and takes charge of her emotional life.

We are not claiming that emotions are inherently passive. ${ }^{\text {li }}$ Rather, we are simply pointing out that a language of passivity, in the Husserlian sense, of "something happening to you" is better at accounting for aesthetic experience, than a language of activity, of "intending" or "willing for something to happen". Further limitations to the term, passivity, should be mentioned. Especially in the case of the DSQ members, it is problematic to claim that while performing, they are passive as if not involved in the performance at all. It should be clear that passivity in this case is a technical Husserlian term denoting the unfolding of consciousness without egoic initiation. Also, the term is prone to the intuition that the passive must be opposed to the active, but this would misrepresent Husserl who considers them on a continuum. ${ }^{\text {xli }}$ As mentioned, there is a rich body of texts from Husserl addressing passive syntheses that, as we have shown, can be used to interpret aesthetic experience. In other words, here is a new application and untapped phenomenological resource for understanding aesthetic experience, which should be of interest and value to researchers of aesthetics and phenomenology alike.

\section{Enactive aesthetics}


Another phenomenologically inspired, recent take on aesthetics can be found in enactivism or enactive aesthetics. ${ }^{x \text { liii }}$ The authors defending this position, however, go about it in a way that seems to contradict our Husserlian presentation, as they stress the inherently active nature of perception and cognition in aesthetic experience. Malafouris for instance regrets that theories of aesthetics often fail to pay "proper attention to the constructive process and materiality of aesthetic creation as a form of action". "As a consequence aesthetics very often looks more like a 'happening' than a 'doing'; something suffered or undergone by a 'patient' rather than actively engaged in." ${ }^{\text {xliv }}$ In the following analysis of Krueger's work, we will show that this enactive criticism does not contradict our Husserlian analysis. If it did it would be problematic, generally because it could expose our position as faulty, but also specifically because enactivism derives much of its philosophical baggage from phenomenology and moreover purports to faithfully describe lived experience, with its insistence on "a deep continuity between mind and life". . $^{\mathrm{l}}$ It would be unfortunate that two positions claiming the same philosophical inheritance contradict one another on a matter as important as aesthetic experience. Enactivism is a line of thinking within the " $4 \mathrm{E}$ cognition" (embodied, embedded, enacted, extended) wave roughly beginning in the 1980s. It covers a number of different but related positions and lines of argumentation that we will not cover in any detail here. ${ }^{\text {xlvi }}$ Rather, we will go straight to Krueger's analyses of music perception as an example of enactive aesthetics and supply with some background enactive theory, where it clarifies his position. Krueger has devoted several publications to an account of enactive music perception and analyzes examples of being on one's own listening to music and of being in an audience attending a concert. ${ }^{\text {xlvii }}$

Imagine going to a large concert hall to indulge in your favorite Beethoven symphony. It would seem that you are going with the purpose of being swept away by the magnificent soundscape of the huge symphony orchestra, with the intention to listen and concentrate on the music, to let your mind be transported to dreamlike, imaginary, beautiful scenarios and to have an uplifting and intense emotional experience. Yet, Krueger argues that this is a case of active "doing" rather than passive "undergoing" : xlviii "Musician and audience are mutually implicated as co-performers and musician, audience, and situation all are in this way part of the enactive dynamic of the music-event, and play a role in determining the content of the perceiver's experience in that context." ${ }^{\text {xlix }}$ Steinhardt from the famous Guaneri String Quartet, can be taken to support Krueger's analysis, writing that it makes a huge difference whether you are performing for someone or not.' Even if the score is set and the interpretation fixed, the music as a whole is determined by moods, memories, and emotions of the musicians, which in turn are shaped by such things as the atmosphere, air, temperature, smell and sound reverberation. Furthermore, at a more intrusive end of the scale, audiences sometimes snore, cough, sneeze, trip and yell or fail to keep their mobiles on silent mode. Even if the main agents of a concert are the musicians, if we are to account for the unfolding music in its 
experienced totality, we must include the role of the audience into the primary unit of analysis. The concert hall, the audience, microphones and musicians together enact one single system that is dynamically coupled such that changes in one end induces further change in the whole system. In other words, the seemingly passive spectators actually play an active role in shaping the experience of the music as heard.

In the theoretical background of Krueger's proposal, we find the enactive thinking of autopoeitic, dynamic systems: According to Thompson, ,i our experience is enacted, or brought forth in dynamic systemic interactions between agents and their environments. We are elements in a coupled system, in which the slightest perturbation in one end reverberates through the entire system. A dynamic system consists primarily of two mutually constraining features. Autopoeisis, or the self-production and self-maintenance of the "autonomous" and "self individuating" part of the system," ii in our case the musician or the particular person in the audience. And the overall sense-making or dynamic of the system considered as a whole, in which the parts are embedded. The parts relate to one another, but under the normative constraints of the system, which they also co-constitute: "An autopoietic system is like $a$ homeostatic system, whereby the homeostatic variable is its own organization." "lii In addition to the agency of the individual parts, the system as such possesses agency and determination over its constituent parts. ${ }^{\text {liv }}$ In the normative space of the concert hall, the spectators are coupled to the musicians and co-determine the overall experience of the outcome of the whole system, namely the music performance. Let us withhold the comparative analysis of how this active role of the audience can be interpreted as a Husserlian passivity and instead turn to another example of Krueger's in which the "spectator" perform a putatively entirely passive role relative to the musical experience.

In another paper, Krueger turns to the experience of listening to music, not in a concert-hall, but through one's headphones or at home through one's speakers. How do we understand such a situation, enactively? It [the music] is an external resource that allows us to cultivate, refine, and explore familiar emotional experiences in new ways - or even develop emotional experiences we may not otherwise have. My thesis... is that it does so by integrating with, and subsequently enhancing, the functional complexity of various endogenous processes responsible for generating and sustaining emotional experience. In some instances, we use the music as an emotion extending tool. We offload some of the regulatory and emotional work onto the music - much the way we offload part of the remembering process onto our social and material environments - and music becomes part of the physical vehicle needed to access certain emotional experiences. ${ }^{\text {Iv }}$

We are not passive recipients in listening to music on our own; we actively use it for emotion regulation. To justify this claim, Krueger relies on work in the sociology of music, notably Tia DeNora's work on Music in Everyday Life. DeNora gives examples from everyday life where people use music to regulate their 
emotions: A woman uses Verdi's requiem in a process of grieving, shuts herself in a room, listening as a form of catharsis. ${ }^{\text {Ivi }}$ We can accept this claim, but still maintain that the listening on its own is a passive act of reception. That listening can be actively used for emotion regulation, does not entail that the perceptual act considered on its own is active. Rather, it merely entails that we make a certain active use of it. In other words, we can distinguish between the phenomenological character of a certain experience and the response to, or context in which we undergo that experience. We saw this earlier in Siv's case of being led to tears by the Hepworth sculpture (the immediate phenomenological character of the experience) and her retracting from the sculpture to return to it later (her response to that initial experience). But Krueger advances an even stronger argument in favour of the inherently active contribution of the listener, not merely as a response of contextual shaping, but as pertaining to the very phenomenological character of aesthetic experience. He coins the term "deep listening", which is an "experience of listening attentively and selectively to a work, engaging with it carefully and opening oneself up to the possibility of being absorbed by the music. lvii Deep listening is "a mode of active perception: an exploration, manipulation, and drawing out of selected emotive properties via our sensorimotor engagement with the music"lviii because this form of listening literally requires a spatial and bodily-based inhabitation of the musical structure. This becomes evident when such inhabitation is lacking, for instance in the case of amusia, the inability to recognize tempo and pitch in music. lix Krueger refers to studies showing that: "amusia is linked not to a specific sensory-musical deficit but rather to a spatial deficit-an inability to represent space" and that: "amusiacs were found to perform significantly worse than non-amusiac control subjects on mental rotation tasks." ${ }^{\prime \mid x}$ From these studies, he makes the following phenomenological interpretation:

it seems that amusiacs are unable...to perceive music as having the sort of spatially inviting structure that might be experientially inhabited-and music thus remains an alien and impenetrable entity. ${ }^{\mid \mathrm{i}}$

"Amusia is thus an inability to perceive and respond to the sensorimotor contingencies afforded by inner space of musical pieces", Ixii which in turn implies that to listen attentively to music is to spatially engage and make sense of the musical landscape. To listen to music as music and not as noise rests on the active contribution of a sense-making, exploratory intentionality, which together with the played music enacts the total meaningful, musical experience.

To understand this proposal, we need to understand what a "sensorimotor engagement with the music" is. ${ }^{\text {Iiii }}$ Here, we turn to Noë's famous dictum that perception is not something we undergo, but something we do. ${ }^{\text {liv }}$ This claim builds on his studies of the nature of perception, coupled with the phenomenological 
idea of the embodiment of subjectivity and Gibson's ecological psychology of affordances. The tradition, like autopoeitic enactivism, has been developed as a response to a naturalistic, cognitivist conception of perception, which it believes has difficulty accounting for a number of perceptual phenomena. ${ }^{{ }^{k v} \mathrm{~A}} \mathrm{An}$ example is what Husserl calls "appresentation", Ixvi the fact that although we do not see the reverse side of objects, they are somehow co-presented in perception. Rather than seeing a world of only front sides, we perceive a practical world with whole, graspable objects that appeal to us in various ways. In other words, we visually perceive much more than we see. From this fact of perception, Noë develops the term "sensorimotor contingencies" or "sensorimotor dependencies": :xvii The constitution of your body and the ways you can move determine what you can see. Perception is not like a camera, passively receiving reflected light into its receptor. It is an embodied explorative activity of reaching out for what is salient and interesting in one's environment. This is what it means for perception to be enacted. When listening to recorded music, unlike the previous example from the concert-hall, one cannot causally impact the unfolding of the music. The recording is a completely closed and self-contained system. But Krueger's point is in order to hear it as music and not noise, I need to employ my sensory-motor abilities and pick out the relevant features of the recording. And, even if the recording is a closed system, I can manipulate what I hear, by exploring or attending to yet other features.

\section{Activity and passivity}

Krueger's enactive view construes aesthetic experience as inherently active. Even the seemingly most passive action, namely listening to music on a stereo or through one's headphones necessarily involves an active meaning-making contribution from the listener. By contrast, our phenomenologically interpreted empirical material shows that aesthetic experience, even in its seemingly most active form, namely that of performing music, centrally revolves around a fundamental receptive and anonymous sense of passivity. How do we account for this seeming contradiction? Let us take a closer look at the notions of passivity employed in the two traditions. On what background does enactivism advance its thesis of the activity of aesthetic experience? As described, the thesis derives from the overall research paradigm of sensory-motor contingencies and dynamic systems, developed as a challenge to orthodox cognitivist theories: "Enactivism explicitly rejects traditional cognitivist notions of mental representations and the passive computational input-output conceptions of cognitive processing so prevalent in cognitive science."|xviii The principle of activity in enactivism is specifically meant to oppose a notion of passivity as "passive computational inputoutput conceptions". The input-output conception of the relation between self and world is static: external sense data stimulates my cognitive apparatus, through the requisite sensory channels, is processed and 
lead to some motor reaction. The enactivist objection to this conception, directly influenced by MerleauPonty ${ }^{\mid x i x}$ is to show how self and world are always already intertwined and how a static conception of interior and exterior is erroneous. This intertwinement is echoed in Thompson's work on dynamic systems in which subjectivity as a whole is enacted, or brought forth in the interaction between the organism and the world around it. As he puts it, the activity of "sense-making...is the living source of intentionality". Ixx Subjectivity and agential activity are not situated inside the head, but are created in the relation between brain, body and world. When applied to the realm of aesthetics, this is not an inaccurate description of the way seeing art activates dormant feelings and memories. When sufficiently open to aesthetic experience, the work of art and the self becomes a sort of dynamic field where emotions, thoughts, memories and hopes are activated, brought forth, or enacted by the system of spectator-artwork-museum.

Husserlian passivity is not equivalent to the passivity in cognitive science against which enactivism reacts. Rather, it helps to found that very criticism by laying bare the conditions of possibility of intertwinement of self and world, qua passivity as negotiator of "ownness and alterity". ${ }^{\text {lxi }}$ Husserlian passivity does not construe bodily perceptual systems as passive receptacles of stimuli. It rather delineates a dynamic substratum of affective and bodily dimensions of subjectivity that underlies and integrates perception into meaningful wholes, as exemplified with the simple perception of a tree outside my window. To distinguish Husserlian passivity from that of orthodox representationalist cognitive science, we from now on label the former "generative passivity". At this point, the argument thus shows us that enactive activity and generative passivity are compatible: there is an entire dimension of subjectivity, normally hidden from sight, ${ }^{1 \times x i i}$ which is exactly not accomplished or initiated by me. Passivity as one single dynamic continuum that can encompass objects (the music or the violin as playing me) my body with its anonymous dimension, and the sense of myself as the subject to whom this continuum unfolds, is compatible with enactment. Neither of them construct impermeable boundaries between self and world, but rather highlight the dynamic meaning-making or sense-making activity binding us into the world and providing the "soil upon which the free activity of the ego moves". Ixxiii Let us return to Krueger to finish the argument.

Krueger argues that the cause of amusia is not an impairment to auditory perception, but rather, that amusiacs fail to construct the requisite mental space necessary to perceive the music as a homogeneous whole. The consequence for normal music listeners, is that even if passively listening, they are actively constructing this meaning-making musical space as a sense-making activity. But whereas Krueger's idea renders this meaning-making an activity, the Husserlian will clearly recognize it as an act of passive synthesis. Who exactly is constructing the meaning-making musical space? It is certainly not something I as listener do actively; it is not an activity of my will. Rather, I am occupied with listening to the music. The 
underlying space is anonymously constructed and "unfolds by itself", Ixxiv its construction is something happening to me. There is nothing I can do to unconstruct this space, once acquired. Surely, I could in an egoic act choose to focus my attention on other elements than the melody or the musical whole, say on the bass line, the harmonic progression or on the meter, and thus construct the musical landscape differently, but that presupposes in the first place, that I am able to perceive the music as music, in other words, that I have a thoroughly engrained and passively constructed habit of listening to this kind of music. We all know this, when becoming acquainted with a musical culture for the first time, be it a Bach Sonata, a movement from Shönberg, an Indian Raga, or song from speed or progressive metal. In the first instance, you mostly hear noise or sounds and cannot perceive or understand the structure and unfolding of the piece. But little by little, you build a habit and make sense of the piece and only then can you move on to deep listening "probing and exploring a piece to unearth new qualities and textures." ${ }^{\prime \mid x x v}$ What's more, for passive habit synthesis, I need internal time consciousness to bind the just-past (retention), the present (primal impression), and the anticipated (protension) into the meaningful whole that we call a melody. Husserl's example par excellence of internal time-consciousness ${ }^{1 \times x v i}$ - one of the passive syntheses - is none other than the melody. The contexts of listening to music, seeing art, but also of performing music are often accompanied by changes in the sense of time flowing, for instance as slowing down or perhaps not passing at all. This sense of a change in time flow, then, is an example of a certain activation and coming to the experiential fore of passive synthesis. In other words, the exercise of habits and internal time consciousness, necessary for a certain construction of musical space, are prime examples of passive synthesis. ${ }^{\text {Ixvii }}$ To Krueger, the amusiac, as an example of deficiency, points to a layer of activity involved even in the seemingly most passive activity and thus demonstrates the enactive thesis. To the Husserlian, however, it is a case of passive synthesis, providing objects as meaningfully perceived.

\section{Conclusion}

We started the section on Krueger's account asking whether enactive aesthetics contradict our Husserlian take, given that he stresses listening to music primarily as a kind of "doing" rather than mere "undergoing". But we have found that the two accounts are in fact compatible. Krueger would probably agree with this, as he also mentions the experience of "letting go" associated with "deep listening". He writes that these are: "heightened experiences of music listening in which we feel as though we are experientially consumed by, and somehow taken up into, the music... Within these experiences, we become acutely aware of the way that "musical agency" (Fritz et al., 2013) profoundly augments, extends, and organizes our own affective resources." ${ }^{\prime \prime x v i i i ~ B e i n g ~ " c o n s u m e d ~ b y ~ a n d ~ s o m e h o w ~ t a k e n ~ u p ~ i n t o " ~ i s ~ c l e a r l y ~ r e m i n i s c e n t ~ o f ~ S i v ' s ~ a e s t h e t i c ~}$ 
experience of "disappearing" or "being in" the work of art and the notion of musical agency has likewise been central to our understanding of the DSQ's phenomenology of absorption. In autopoeitic enactive technical terms we may thus interpret the experience of being overwhelmed and consumed by the work of art or fused with it as a situation where the balance between the "self-individuating" parts of the system and its overall dynamic coupling is momentarily pushed toward the latter, with a weaker sense of selfpreservation in favor of a greater sense of coupling.

We welcome the attempt to balance the inherently passive dimension of aesthetic experience with the active mental contribution that the enactive perspective highlights and which we in the Husserlian context have called "generative" and we urge enactivists to give it prominence in future accounts, so as to live up to their intended "deep continuity of mind and life". Ixxix Ultimately, our aim is not to reduce incredible complex aesthetic experiences to pure passivity. Roald's concept "intrapellation", Dufrenne's "feeling" and Bertram's "dependence in independence ${ }^{\prime \prime \mid x x}$ all point to the intricate relation between activity and receptivity in aesthetic experience. In this article we have simply highlighted the passive dimension in aesthetic experience and elucidated that the experience of "letting go" or becoming absorbed is complex, multilayered and calls for further analysis. We have shown that passivity is essential and that in the realm of aesthetics, being overwhelmed, struck or surprised means undergoing an experience that one did not initiate, it means that the passive basis of the experience is phenomenally heightened.

\section{Bibliography}

Ayotte J., Peretz I., and Hyde K. "Congenital amusia: A group study of adults afflicted with a music-specific disorder." Brain, 125 (2002): 238-51.

Bastian, P. Ind I Musikken: En Bog om Musik og Bevidsthed. København: Gyldendal A/S, 1987

Benson, C. The Absorbed Self: Pragmatism, Psychology, and Aesthetic Experience. Hemel Hempstead: Harvester Wheatsheaf, 1993.

Bertram, G. A"esthetic experience as an aspect of interpretative activities." Comparative Studies in Modernism. 6 (spring) (2015): 65-74.

Biceaga, V. The Concept of Passivity in Husserl's Phenomenology. Vol. 60. Contributions to Phenomenology. Dordrecht: Springer Netherlands, 2010.

Bullough, E. "The modern conception of æsthetics". (1907). Reprinted in (Ed. E. M. Wilkinson) AEsthetics: Lectures and essays: 1-89. Stanford: Stanford University Press, 1957.

Casey, E. "Aesthetic Experience." in (Eds.) H. R. Sepp \& L. Embree Handbook of Phenomenological Aesthetics. New York: Springer (2010): 1-8. 
Clark, A. and Chalmers, D. "The Extended Mind." Analysis, (1998): 7-19.

Colombetti, G. The Feeling Body: Affective Science Meets the Enactive Mind. Cambridge, MA: MIT Press, 2014.

De Jesus, P. "Autopoietic enactivism, phenomenology and the deep continuity between life and mind." Phenomenology and the Cognitive Sciences 15 (2016):265-289.

DeNora, T. Music in Everyday Life. Cambridge; New York: Cambridge University Press, 2004.

De Sousa, R. The Rationality of Emotion. Cambridge, MA: MIT Press, (1990).

Dewey, J. Art as Experience. New York: Perigee Books, 1980.

Di Paolo, E. “Extended Life.” Topoi 28 (2009):9-21.

--- \& Thompson, E. "The Enactive Approach." In Ed. (L. Shapiro) The Routledge Handbook of Embodied Cognition. London: Routledge (2014): 68-78.

- - , Buhrmann, T, and Barandiaran, X. E. Sensorimotor Life. An Enactive Proposal. Oxford: Oxford University Press, 2017.

Dufrenne, M. The phenomenology of Aesthetic Experience. Evanston: Northwestern University Press, 1973.

Gallagher, S. "Body Image and Body Schema: A Conceptual Clarification." Journal of Mind and Behavior 7 (4) (1986): 541-554.

- - "Phenomenology and Experimental Design: Toward a Phenomenologically Enlightened Experimental Science." Journal of Consciousness Studies 10(9-10) (2003): 85-99.

- - "The Natural Philosophy of Agency." Philosophy Compass 2 (2) (2007): 347-57.

- - "Multiple Aspects in the Sense of Agency." New Ideas in Psychology 30 (1) (2012): 15-31.

- - Enactivist Interventions. Oxford: Oxford University Press, 2017.

Giorgi, A. The descriptive phenomenological method in psychology : a modified Husserlian approach. Pittsburgh: Duquesne University Press, 2009.

- - "The descriptive phenomenological psychological method." Journal of Phenomenological Psychology, 43(1) (2012): 3-12.

Husserl, E. Cartesian Meditations. An Introduction to Phenomenology. The Hague: Martinus Nijhoff, 1960.

- - The Phenomenology of Internal Time-Consciousness. Bloomington; London: Indiana University Press, 1966.

-_- Experience and Judgment. Evanston: Northwestern University Press, 1973.

---Ideas Pertaining to a Pure Phenomenology and to a Phenomenological Philosophy: Second Book. Studies in the Phenomenology of Constitution. Dordrecht: Kluwer Academic Publishers, 1990. 
- - Thing and Space. Lectures of 1907. Dordrecht: Kluwer Academic Publishers, 1997.

- - Analyses Concerning Passive and Active Synthesis: Lectures on Transcendental Logic. Vol. 9. Dordrecht: Kluwer Academic Publishers, 2001.

Hutto, D. \& Myin, E. Radicalizing Enactivism. Basic Minds without Content. Cambridge, MA: MIT Press, 2013.

Hytönen-Ng, E. Experiencing "Flow" in Jazz Performance. Farnham, UK and Burlington VT, USA: Ashgate Publishing, Ltd. 2013.

Høffding, S. "Performative Passivity: Lessons on phenomenology and the extended musical mind with the Danish String Quartet." In Music \& Consciousness II, edited by David Clarke, Ruth Herbert, and Eric Clarke. Oxford: Oxford University Press, in press.

_-_ A Phenomenology of Musical Absorption. London: Palgrave Macmillan, 2019.

- - - and Martiny, K. "Framing a Phenomenological Interview: What, Why and How." Phenomenology and the Cognitive Sciences 15 (4) (2016): 539-64.

Kelly, S. "On Seeing Things in Merleau-Ponty." in (Eds.) T. Carmon and M. Hansen Cambridge Companion to Merleau-Ponty. Cambridge: Cambridge University Press (2005): 74-110.

Kimura, B. L'entre: une approche phénoménologique de la schizophrénie. Grenoble: Editions Jérôme Millon, 2000.

Krueger, J. “Enacting Musical Experience." Journal of Consciousness Studies. 16 (2-3) (2009): 98-123.

- - "Musical Manipulations and the Emotionally Extended Mind." Empirical Musicology Review. 9 (3) (2014a):208-12.

- - "Affordances and the Musically Extended Mind." Frontiers in Psychology. 4 (Article 1003) (2014b):

$1-13$.

Leder, D. The Absent Body. Chicago: The University of Chicago Press, 1990.

Legrand, D. "Pre-Reflective Self-Consciousness: On Being Bodily in the World." Janus Head 9 (2) (2007): 493-519.

Lipps, T. Ästhetik: Psychologie des Schönen und der Kunst. 2 vols. Hamburg: Leopold Voss, 1903/06.

Lotz, C. From Affectivity to Subjectivity: Husserl's Phenomenology Revisited. Hampshire: Palgrave Macmillan, 2007.

Maiese, M. "Can the mind be embodied, enactive, affective and extended?" Phenomenology and the Cognitive Sciences. (2017) DOI 10.1007/s11097-017-9510-6

Malafouris, L. "The Aesthetics of Material Engagement." In (Ed.) R. Manzotti Situated Aesthetics. Art beyond the Skin. Exeter, UK: Imprint Academic (2011): 171-94. 
- - - How things shape the mind. Cambridge, MA: MIT Press, 2013.

Mohanty, J. N. Edmund Husserl's Freiburg Years: 1916-1938. New Haven: Yale University Press, 2011.

Montavont, A. De La Passivité Dans La Phénoménologie de Husserl. Èpiméthée. Paris: Presses Universitaires de France, 1999.

Montero, B. Thought in Action: Expertise and the Conscious Mind. Oxford: Oxford University Press, 2016.

Nanay, B. “Aesthetic Attention." Journal of Consciousness Studies, 22, 5-6 (2015): 96-118.

Noë, A. Action in Perception. Cambridge, MA: MIT Press, 2006.

\& Thompson, E. (Eds.) Vision and Mind. Cambridge, MA: MIT Press, 2002.

Petitmengin, C. "Describing one's subjective experience in the second person: An interview method for the science of consciousness." Phenomenology and the Cognitive Sciences. 5(3-4) (2006): 229-269.

Puffer, E. The Psychology of Beauty. Boston: Houghton Mifflin Company, 1905.

Ravn, S. "Phenomenological analysis in sport and exercise." in (Eds. B. Smith \& A. C. Sparkes) Routledge Handbook of Qualitative Research in Sport and Exercise. London: Routledge (2016): 206218.

Roald, T. Cognition in emotion: An investigation through experiences with art. Amsterdam, New York: Rodopi, 2007.

Roald, T. "Toward a phenomenological psychology of art appreciation." Journal of Phenomenological Psychology, 39(2) (2008): 189-212.

Roald, T. The Subject of Aesthetics. Leiden: Brill, 2015.

Sacks, O. Musicophilia: Tales of music and the brain. London: Picador, 2007.

Shapiro, L. (Ed.) The Routledge Handbook of Embodied Cognition. London: Routledge, 2014.

Steinhardt, A. Indivisible by Four. New York: Farrar Straus Giroux, 1998.

Sutton, J., Mcllwain, D., Christensen, W., and Geeves, A. "Applying Intelligence to the Reflexes: Embodied Skills and Habits between Dreyfus and Descartes." The Journal of the British Society for Phenomenology 42 (1) (2011): 78-103.

Thompson, E. Mind in Life: Biology, Phenomenology, and the Sciences of Mind. London: Belknap Press, 2007.

- - “Living Ways of Sense Making." Philosophy Today 55 (2011): 114-23.

Varela, F., Thompson, E. and Rosch, E. The Embodied Mind: Cognitive Science and Human Experience. Cambridge, MA: MIT Press, 1991. 
Waldenfels, B. "Bodily Experience between Selfhood and Otherness." Phenomenology and the Cognitive Sciences 3 (3) (2004): 235-48.

Zahavi, D. Self-Awareness and Alterity: A Phenomenological Investigation. Northwestern University Press, 1999.

"Unity of Consciousness and the Problem of the Self." in (Ed.) S. Gallagher The Oxford Handbook of the Self. Oxford: Oxford University Press (2013): 316-35.

Danish String Quartet website: www.danishquartet.com

\footnotetext{
' We are grateful to Felipe Leon, Dave Ward, Joel Krueger, Kasper Levin, Bjarne Sode Funch, Simo Køppe, Jannik Mosekjær Hansen, Anders Essum-Stenz, Tom Teasdale, and two anonymous reviewers for very helpful suggestions to improve this paper. Research for this paper was supported by the Independent Research Fund, Denmark under grant number DFF-6107-00273.

ii Casey, "Aesthetic Experience".

iii Krueger "Enacting Musical Experience"; "Musical Manipulations"; "Affordances Extended Mind"; Malafouris

"Aesthetics of Material Engagement"; How things shape the mind.

iv This is close to Bence Nanay's rather non-committal take (Nanay, "Aesthetic attention").

"Giorgi, Descriptive phenomenological method; "descriptive phenomenological psychological method".

vi Ravn, "phenomenological analysis".

vii Gallagher, "Phenomenology and experimental design".

viii Petitmengin, "Describing subjective experience".

ix Høffding and Martiny, "Framing a phenomenological interview"; Roald, Cognition in emotion,; "psychology of art appreciation"; The subject of aesthetics.

${ }^{x}$ The examples we have selected are from those participants who describe their most intense experiences with art. A few participants described experiences of dislike and these interviews were not selected for analysis in this paper. ${ }^{x i}$ see also Roald, Subject of aesthetics.

xii Montero, Thought in action, chap. 10. Dewey, likewise, asserts that the artistic cannot be separated from the aesthetic, that the artist is not only "doing", but also "undergoing" (Dewey, Art as experience, 47-48).

xiii See www.danishquartet.com

${ }^{\text {xiv }} \mathrm{H} \varnothing \mathrm{ffding,} \mathrm{Phenomenology} \mathrm{of} \mathrm{musical} \mathrm{absorption.}$

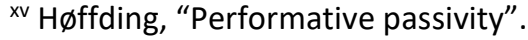

xvi See Høffding, Phenomenology of musical absorption, Sutton et al. "Applying intelligence", and Montero, Thought in action for further work on the interpenetration of thinking and bodily action.

xvii Kimura, L'entre, 42.

xviii Colombetti, The feeling body, chap. 5)

xix as indicated by Hytönen, Experiencing "flow", 84-5)

xx Gallagher, "Body image and schema".

xxi The bassoonist, Peter Bastian, likewise asks "who is playing?" experiencing his performances as if it was not himself playing, but the "music...playing itself" (Bastian, Ind I musikken, 160-1).

xxii In contrast to pleasantly overwhelming experiences, unpleasantly overwhelming experiences of breakdown also occur. Examples from the DSQ members involve performing while day-dreaming so intensely that one misses one's entry or hearing the physical collapse of an audience member and wondering whether to call an ambulance. See Høffding, Phenomenology of musical absorption, chap. 4 for elaboration.

xxiii Legrand, "pre-reflective self-consciousness", 506.
} 
xxiv Steinbock in Husserl, Passive and active synthesis; Biceaga, Concept of passivity; Montavont, De la passivité: Zahavi, Self-awareness and alterity; "Unity of consciousness"; Lotz, From affectivity to subjectivity; Mohanty, Edmund Husserl's Freiburg years; Waldenfels, "Bodily experience".

${ }^{x \times v}$ Steinbock in Husserl, Passive and active synthesis, xliii.

xxvi Biceaga, Concept of passivity, 95.

xxvii From now on we shall use the two terms synonymously.

xxviii Husserl, Ideas second book, 22.

xxix Husserl, Passive and active synthesis, 368 \& 631.

${ }^{\mathrm{xxx}}$ see Leder, The absent body.

${ }^{x \times x i}$ see Roald, Subject of aesthetics, for more work on the relation between art and subjectivity.

xxxii Montavont, De la passivité, 103-4; Høffding's translation.

xxxiii Zahavi, "Unity of consciousness", 323.

xxxiv Husserl, Ideas second book, 347.

xxxv See Gallagher, "Body Image and Schema", 549, on the connection between agency and bodily anonymity.

xxxvi Gallagher, "Natural philosophy of agency"; "Multiple aspects".

xxxvii There is a sense in which the "I" is never the initiator because it always rests on preceding passive syntheses.

Phenomenally, however, we usually experience ourselves as initiators of action and the point of aesthetic experience is that the balance is gradually shifted toward experiencing ourselves as undergoers.

xxxviii The relation between self and other in passive synthesis is complicated and spelled out in greater detail in

Høffding, "Performative Passivity".

xxxix The expansion of agency as well as incorporation of instrument and musical setting described, is not identical to the "extended mind hypothesis" (Clark and Chalmers, "The extended ind".) among other reasons because the case here described involves a changed experience of the boundary of my body, which does not necessarily pertain to the classical extended mind cases.

${ }^{x l}$ Husserl, Ideas second book, 104.

xli See for instance de Sousa, The rationality of emotion. See also see Roald, Cognition in emotion, for a discussion of various configurations of emotionality.

xlii Husserl, Ideas second book, 225; Montavont, De la passivité, 88.

xliii Krueger, "Enacting Musical Experience"; "Musical Manipulations"; “Affordances Extended Mind”; Malafouris "Aesthetics of Material Engagement"; How things shape the mind.

xliv Malafouris "Aesthetics of Material Engagement", 178.

xlv Thompson, Mind in life, 128.

xlvi See for instance Varela, Thompson \& Rorsch, The embodied mind; Thompson, Mind in life; Gallagher, Enactivist interventions 2017; Di Paolo, Buhnman \& Barandiaran, Sensorimotor life; Hutto and Myin, Radicalizing enactivism; Shapiro, Routledge handbook of embodied cognition.

xlvii Krueger, "Enacting Musical Experience"; "Musical Manipulations"; "Affordances Extended Mind”.

xlviii Krueger, "Enacting Musical Experience", 104.

xlix Ibid., 116.

'Steinhardt, Indivisible by four, 135-6. Steinhardt is here writing on the difference between performing and recording.

li Thompson, Mind in life.

lii Di Paolo and Thompson, "The enactive approach", 68.

liii Di Paolo, "Extended life", 13.

liv The core concepts used here are all rich and not without problems. For a more rigorous systematic treatment, see Thompson, "Living ways of sense making"; Di Paolo, "Extended life"; De Jesus "Autopoietic enactivism"; Maiese, "Can the mind be embodied".

Iv Krueger, "Musical manipulations", 209.

Ivi DeNora, Music in everyday life, 58.

Ivii Krueger, "Enacting Musical Experience", 104.

Iviii Ibid. 107.

lix Ayotte, Peretz \& Hyde, "Congenital amusia"; Sacks, Musicophilia.

${ }^{\mathrm{I}}$ Krueger, "Enacting Musical Experience", 119.

Ixi Ibid.

Ixii Ibid.

Ixiii Ibid., 107.

Ixiv Noë, Action in perception, 1. 
Ixv Noë \& Thompson, Vision and mind.

Ixvi Husserl, Cartesian meditations, § 50; Thing and space, chap.3. See also Kelly, "On seeing things", 77-8 for MerleauPonty's take on the matter.

Ixvii Noë, Action in perception.

Ixviii De Jesus, “Autopoietic enactivism”, 267.

kxix See Thompson, Mind in life, chaps. 2 \& 4.

Ixx Thompson, "Living ways of sense making", 6.

Ixxi Biceaga, Concept of passivity, 95.

Ixxii This unnoticed dimension of subjectivity should not be confused with a Freudian or Lacanian idea of the unconscious.

Ixxiii Husserl, Passive and active synthesis, 386.

Ixxiv Montavont, De la passivité, 104; Høffding's translation.

Ixxv Krueger, "Enacting Musical Experience", 114.

Ixxvi Husserl, Internal time-consciousness.

Ixxvii Husserl, Passive and active synthesis, 368 \& 631. In regards to habits as passivity, Biceaga writes: "The modifications accruing to synthetic accomplishments after the corresponding egoic acts have been carried out constitute the sphere of secondary passivity. The most prominent phenomena belonging to this sphere are the phenomena of sedimentation, that is, reproductive associations and habitus." Biceaga, Concept of passivity, xviii. Ixxviii Krueger, "Affordances Extended Mind", 7.

${ }^{\text {Ixxix }}$ Another indicator that Husserlian passivity has a role to play in enactivism can be found when Thompson, though in passing, mentions passive synthesis in Mind in Life (29-30) and "passive synthesis - passivity, receptivity, and affect" in later work as partly constitutive of sense-making (Thompson, "Living ways of making sense", 6.

Ixxx Roald, Subject of aesthetics; Dufrenne, The phenomenology of aesthetic experience, chap. 14; Bertram, "Aesthetic experience", 70. 